\title{
Inhibition of the calcium-activated chloride current in cardiac ventricular myocytes by $\mathrm{N}$-(p-amylcinnamoyl)anthranilic acid (ACA)
}

\author{
Asfree Gwanyanya ${ }^{\mathrm{a}, 1}$, Regina Macianskiene ${ }^{\mathrm{a}, \mathrm{b}}$, Virginie Bito ${ }^{\mathrm{c}}$, Karin R. Sipido ${ }^{\mathrm{c}}$, Johan Vereecke ${ }^{\mathrm{d}}$, \\ Kanigula Mubagwa ${ }^{\mathrm{a}, *}$ \\ a Division of Experimental Cardiac Surgery, Department of Cardiovascular Diseases, University of Leuven, Leuven, Belgium \\ ${ }^{\mathrm{b}}$ Laboratory of Membrane Biophysics, Institute of Cardiology, Kaunas University of Medicine, Kaunas, Lithuania \\ ${ }^{\mathrm{c}}$ Laboratory of Experimental Cardiology, Department of Cardiovascular Diseases, University of Leuven, Leuven, Belgium \\ ${ }^{\mathrm{d}}$ Laboratory of Physiology, Department of Cellular and Molecular Biology, University of Leuven, Leuven, Belgium
}

\section{A R T I C L E I N F O}

\section{Article history:}

Received 5 October 2010

Available online 28 October 2010

\section{Keywords:}

Cardiac

Chloride channel

Calcium-activated

$N$-(p-amylcinnamoyl)anthranilic acid

Diclofenac

\begin{abstract}
A B S T R A C T
$N$-(p-amylcinnamoyl)anthranilic acid (ACA), a phospholipase $\mathrm{A}_{2}\left(\mathrm{PLA}_{2}\right)$ inhibitor, is structurally-related to non-steroidal anti-inflammatory drugs (NSAIDs) of the fenamate group and may also modulate various ion channels. We used the whole-cell, patch-clamp technique at room temperature to investigate the effects of ACA on the $\mathrm{Ca}^{2+}$-activated chloride current $\left(I_{\mathrm{Cl}(\mathrm{Ca})}\right)$ and other chloride currents in isolated pig cardiac ventricular myocytes. ACA reversibly inhibited $I_{\mathrm{Cl}(\mathrm{Ca})}$ in a concentration-dependent manner $\left(\mathrm{IC}_{50}=4.2 \mu \mathrm{M}, n_{\text {Hill }}=1.1\right.$ ), without affecting the L-type $\mathrm{Ca}^{2+}$ current. Unlike ACA, the non-selective PLA 2 inhibitor bromophenacyl bromide (BPB; $50 \mu \mathrm{M})$ had no effect on $I_{\mathrm{Cl}(\mathrm{Ca})}$. In addition, the analgesic NSAID structurally-related to ACA, diclofenac $(50 \mu \mathrm{M})$ also had no effect on $I_{\mathrm{CI}(\mathrm{Ca})}$, whereas the current in the same cells could be suppressed by chloride channel blockers flufenamic acid (FFA; $100 \mu \mathrm{M})$ or 4,4'-diisothiocyanostilbene-2,2'-disulfonic acid (DIDS; $100 \mu \mathrm{M})$. Besides $I_{\mathrm{CI}(\mathrm{Ca})}$, ACA $(50 \mu \mathrm{M})$ also suppressed the cAMP-activated chloride current, but to a lesser extent. It is proposed that the inhibitory effects of ACA on $I_{\mathrm{CI}(\mathrm{Ca})}$ are $\mathrm{PLA}_{2}$-independent and that the drug may serve as a useful tool in understanding the nature and function of cardiac anion channels.
\end{abstract}

(c) 2010 Elsevier Inc. All rights reserved.

\section{Introduction}

Chloride channels that are activated by intracellular $\mathrm{Ca}^{2+}$ are present in various tissues where they are involved in different physiological functions [1]. In the heart, $\mathrm{Ca}^{2+}$-activated $\mathrm{Cl}^{-}$currents $\left(I_{\mathrm{Cl}(\mathrm{Ca})}\right)$ have been identified in atria [2], ventricles [3-5] and Purkinje fibres [6] of different animal species. Functionally, the cardiac $I_{\mathrm{Cl}(\mathrm{Ca})}$ participates in the early phase of repolarization during an action potential $[3,7]$. Under disease conditions, the transient inward component of $I_{\mathrm{Cl}(\mathrm{Ca})}$ has been implicated in arrhythmogenesis $[8,9]$.

Abbreviations: ACA, $N$-( $p$-amylcinnamoyl)anthranilic acid; DIDS, 4,4'-diisothio-

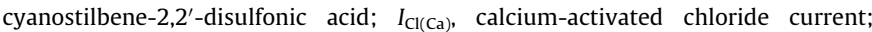
$I_{\mathrm{Cl}(\mathrm{cAMP})}$, cyclic AMP-activated chloride current; $I_{\text {to }}$, transient outward current; NPPB, 5-nitro-2-(3-phenylpropylamino)benzoic acid; NSAID, non-steroidal antiinflammatory drug; $\mathrm{PLA}_{2}$, phospholipase $\mathrm{A}_{2}$; TRP, transient receptor potential.

* Corresponding author. Address: Campus Gasthuisberg, Herestraat 49, Box 705, B-3000 Leuven, Belgium. Fax: +32 16347139.

E-mail address: kanigula.mubagwa@med.kuleuven.be (K. Mubagwa).

${ }^{1}$ Present address: Department of Human Biology, Faculty of Health Sciences, University of Cape Town, Cape Town, South Africa.
Despite the importance of $\mathrm{Ca}^{2+}$-activated chloride channels, progress in understanding their structure, function and regulation has been limited by the uncertainty about the underlying channel protein and a lack of specific antibodies (see [10] for review). As a result, pharmacological agents still provide the major tools to study these channels. The agents include structurally diverse chemicals such as 5-nitro-2-(3-phenylpropylamino)-benzoic acid (NPPB), disulfonic stilbene derivatives like 4,4'-diisothiocyanostilbene-2,2'-disulfonic acid (DIDS) and the non-steroidal anti-inflammatory drugs (NSAIDs) of the fenamate group like flufenamic and niflumic acids. However, most of the drugs available to inhibit $\mathrm{Ca}^{2+}$-activated $\mathrm{Cl}^{-}$channels are only effective at high concentrations and are non-specific. For example, NPPB also blocks L-type $\mathrm{Ca}^{2+}$ currents [11], whereas niflumic acid not only inhibits but also partly stimulates $I_{\mathrm{Cl}(\mathrm{Ca})}[12]$ and may cause release of $\mathrm{Ca}^{2+}$ from intracellular stores $[13,14]$. In addition, disulfonic stilbene derivatives are mostly effective at high concentrations and their effects are not readily reversible. Consequently, additional drugs that modulate $I_{\mathrm{Cl}(\mathrm{Ca})}$ could be valuable in developing more specific inhibitors as well as in providing further insights into the functional role and nature of the channels. Among drugs structurallyrelated to fenamates is $N$-( $p$-amylcinnamoyl)anthranilic acid 
(ACA), also known to inhibit phospholipase $\mathrm{A}_{2}$ (PLA 2 ; [15]). Here, we show that ACA inhibits $I_{\mathrm{Cl}(\mathrm{Ca})}$ in a concentration-dependent manner without affecting L-type $\mathrm{Ca}^{2+}$ currents.

\section{Materials and methods}

\subsection{Cell isolation and electrophysiology techniques}

The study was approved by the Ethical Commission on Animal Experiments of the University of Leuven and carried out according to the institutional guidelines for laboratory animal care. We used ventricular myocytes dissociated from pig by methods described in detail before [16-18]. Briefly, pigs were anesthetized with sodium pentobarbitone (5-15 $\mathrm{mg} \mathrm{kg}^{-1}$ I.V.), intubated and ventilated, and then injected with heparin (5-8 $\mathrm{mg} \mathrm{kg}^{-1}$ I.V.) and a sodium pentobarbitone overdose $\left(100 \mathrm{mg} \mathrm{kg}^{-1}\right)$ before tissue extraction. Cells were dissociated by enzymatic tissue digestion during Langendorff perfusion. All experiments were performed at room temperature. The voltage-clamp protocols consisted of either steps from the holding potential of $-80 \mathrm{mV}$ to various levels or 4-s symmetrical ramps from -120 to $+80 \mathrm{mV}$ and back to $-120 \mathrm{mV}$, applied every $10 \mathrm{~s}$. During the ascending limb of the ramp, the slow rate of depolarization $(0.1 \mathrm{~V} / \mathrm{s})$ allowed activation and inactivation of the voltage-dependent $\mathrm{Na}^{+}$current. Currents were measured during the descending limb of the ramp. The pClamp 8.1 software was used to generate voltage protocols and to record data via a Digidata 1322A acquisition system (Axon instruments, Union City, CA, USA).

\subsection{Solutions and drugs}

The standard Tyrode solution used during cell dissociation contained (in mM): $135 \mathrm{NaCl}, 5.4 \mathrm{KCl}, 0.9 \mathrm{MgCl}_{2}, 1.8 \mathrm{CaCl}_{2}, 0.33 \mathrm{NaH}_{2} \mathrm{PO}_{4}$, 10 HEPES and 10 glucose; $\mathrm{pH}$ was adjusted to 7.4 with $\mathrm{NaOH}$. During voltage clamp measurements, cells were superfused with a solution of similar composition except that $\mathrm{K}^{+}$was replaced by $\mathrm{Cs}^{+}$. When studying $\mathrm{Ca}^{2+}$-activated $\mathrm{Cl}^{-}$currents, $\mathrm{Na}^{+}$-free solutions (with $\mathrm{Na}^{+}$replaced by $\mathrm{NMDG}^{+}$) were used to eliminate the voltage-dependent $\mathrm{Na}^{+}$ currents. For low $\mathrm{Cl}^{-}$solutions, $\mathrm{Cl}^{-}$was replaced by glutamate or by methylsulfate. The standard pipette solution contained (in $\mathrm{mM}$ ): 130 Cs-glutamate, 25 TEA-Cl, $5.5 \mathrm{MgCl}_{2}, 5 \mathrm{Na}_{2} \mathrm{ATP}, 1$ EGTA, $0.1 \mathrm{Na}_{2} \mathrm{GTP}, 5$ HEPES ( $\mathrm{pH} 7.25$; adjusted with $\mathrm{CsOH}$ ) and was modified in a few experiments by replacing EGTA with BAPTA.

ACA was obtained from Tebu-Bio (Boechout, Belgium). All other drugs or chemicals were from Sigma-Aldrich (Bornem, Belgium) or Merck (Darmstadt, Germany). Nifedipine was prepared as stock solution in ethanol, whereas ACA, bromophenacyl bromide, DIDS, flufenamic acid and forskolin were prepared in DMSO. All other chemicals were dissolved in water.

\subsection{Data and statistical analyses}

Data were analyzed using Clampfit 8.2 (Axon Instruments) and Origin 7 (Microcal, USA). The following Hill equation was used to fit the inhibiting effects of ACA as a function of concentration:

Relative current $=I_{[D]} / I_{\max }=1 /\left[1+\left([D] / \mathrm{IC}_{50}\right)^{n_{\text {Hill }}}\right]$,

where $I_{[D]}$ is the current at a given drug concentration $[D], I_{\max }$ is the current in the absence of the drug, $\mathrm{IC}_{50}$ is the drug concentration for $50 \%$ inhibition, and $n_{\text {Hill }}$ is the Hill coefficient. Average data are expressed as mean \pm standard error of the mean, with $n$ indicating the number of cells studied. Means were compared using the two-tailed Student's $t$-test. $P \leqslant 0.05$ was taken as threshold for statistical significance.

\section{Results}

\subsection{The $\mathrm{Ca}^{2+}$-activated chloride current $\left(\mathrm{I}_{\mathrm{Cl}(\mathrm{Ca})}\right)$ in pig cardiac ventricular myocytes}

Fig. 1A illustrates typical whole-cell current traces obtained using voltage steps between -80 and $+60 \mathrm{mV}$ (see inset) in $\mathrm{Na}^{+}-$ free conditions. The steps induced capacitive transients, which (at potentials $>-40 \mathrm{mV}$ ) were followed by short-lived biphasic currents with brief inward and prominent outward components (Fig. 1A, panel $a$; see also left panels of Figs. 2A and 3B and C). Both inward and outward currents could be completely suppressed by nifedipine (5-100 $\mu \mathrm{M} ; n=15$; not illustrated), suggesting that the biphasic currents may be due to superimposed inward L-type $\mathrm{Ca}^{2+}$ currents $\left(I_{\mathrm{Ca}, \mathrm{L}}\right)$ and a $\mathrm{Ca}^{2+}$-activated outward current. We tested the hypothesis that the outward current was a $\mathrm{Cl}^{-}$current $\left(I_{\mathrm{Cl}(\mathrm{Ca})}\right)$ by removing extracellular chloride $\left(\mathrm{Cl}_{\mathrm{o}}^{-}\right)$and by using $\mathrm{Cl}^{-}$ channels inhibitors. When $\mathrm{Cl}_{\mathrm{o}}^{-}$was replaced by glutamate, the currents induced by depolarization became monophasic inward with no outward component (Fig. 1A, panel $b$ ). This effect was reversible upon re-admission of $\mathrm{Cl}_{\mathrm{o}}^{-}$(Fig. $1 \mathrm{~A}$, panel $c$ ). In the presence of $\mathrm{Cl}_{\mathrm{o}}^{-}$, flufenamic acid $(100 \mu \mathrm{M})$, a known $\mathrm{Cl}^{-}$channel inhibitor, suppressed the outward transients, leaving inward currents resembling those in $\mathrm{Cl}^{-}$-free solutions (Fig. 1A, panel $d$; similar results in seven cells). DIDS $(100 \mu \mathrm{M})$, another $\mathrm{Cl}^{-}$channel inhibitor, also suppressed the outward transients, but to a lesser extent $(n=4$; not illustrated). Fig. 1B shows that the $\mathrm{Cl}^{-}$-dependent current, calculated as the difference between the current in the presence of $\mathrm{Cl}_{\mathrm{o}}^{-}$ and that after $\mathrm{Cl}_{\mathrm{o}}^{-}$removal, had a maximum value $(1.46 \pm 0.26 \mathrm{pA} /$ $\mathrm{pF} ; n=5$ ) at $+25 \mathrm{mV}$. Furthermore, in five other cells dialyzed with $10 \mathrm{mM}$ BAPTA-containing solution and treated with $10 \mu \mathrm{M}$ ryanodine in the external solution to prevent sarcoplasmic $\mathrm{Ca}^{2+}$ release, only $I_{\mathrm{Ca}, \mathrm{L}}$ was observed (see Fig. $2 \mathrm{~B}$, left panel), demonstrating a dependence of the outward current on intracellular $\mathrm{Ca}^{2+}$. Taken together, these results indicate that the transient outward current observed in our experiments is $I_{\mathrm{Cl}(\mathrm{Ca})}$ and are consistent with those by others showing the presence of $I_{\mathrm{Cl}(\mathrm{Ca})}$ in pig ventricular myocytes [19].

In contrast to the effect on the transient currents elicited at potentials $>-40 \mathrm{mV}$, the removal of $\mathrm{Cl}_{0}^{-}$did not affect the steadystate current in the same cells (Fig. 1C), indicating that the $\mathrm{Cl}_{\mathrm{o}}^{-}$removal was not altering background conductance.

\subsection{Effects of $N$-(p-amylcinnamoyl)anthranilic acid (ACA)}

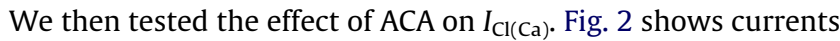
obtained using depolarizing steps, in control conditions and in the presence of ACA. Upon application of ACA $(20 \mu \mathrm{M})$ outward components were suppressed (Fig. 2A, middle panel), an effect that was reversible upon drug washout (not illustrated). The ACA-sensitive current at various potentials (calculated as the difference between control current and the current during ACA application) is shown in Fig. 2A (right panel). Its current-voltage relationship in five cells (Fig. 2C, open symbols) is similar to that of the $\mathrm{Cl}^{-}$-dependent current (see Fig. 1B). To exclude the possibility that the effect of ACA could be due to an enhancement of $I_{\mathrm{Ca}, \mathrm{L}}$, with a masking of a superimposed outward current, we tested the effect of ACA under conditions where intracellular $\mathrm{Ca}^{2+}$ release was inhibited with ryanodine and cytosolic $\mathrm{Ca}^{2+}$ was highly buffered with BAPTA. Outward transients were absent in BAPTA-dialyzed and ryanodinetreated cells (Fig. 2B, left panel), and the control current $\left(I_{\mathrm{Ca}, \mathrm{L}}\right.$ uncontaminated by $I_{\mathrm{Cl}(\mathrm{Ca})}$ ) was not affected by ACA (Fig. 2B, middle panels; $103 \pm 7 \%$ of control at $0 \mathrm{mV} ; P=0.548$ compared with control; paired $t$-test, $n=5$ ), i.e. the ACA-sensitive current was practically zero at all tested voltages (Fig. 2B, right panel, and C, filled 
A

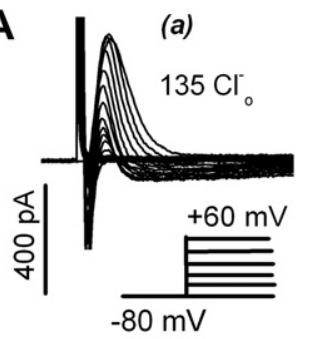

B $\mathrm{Cl}^{-}$-dependent peak current

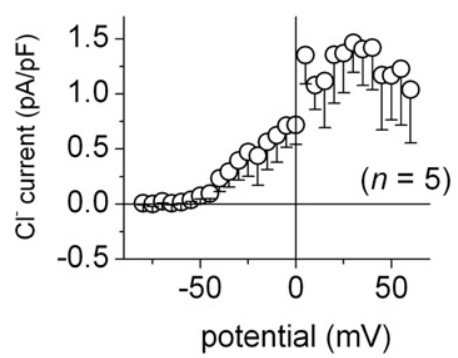

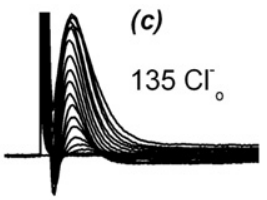

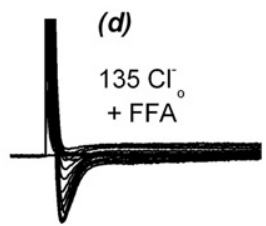

$100 \mathrm{~ms}$

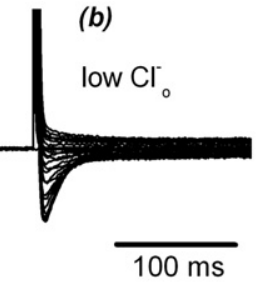

\section{C}

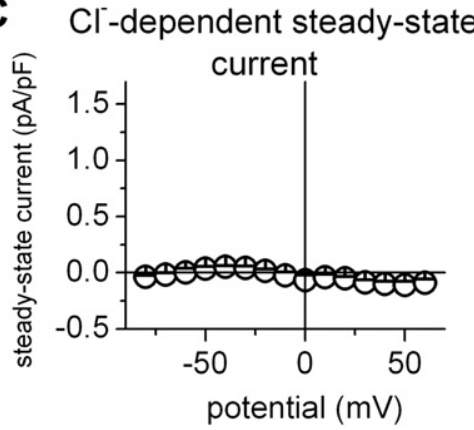

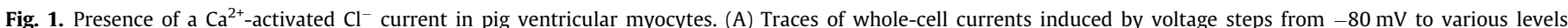

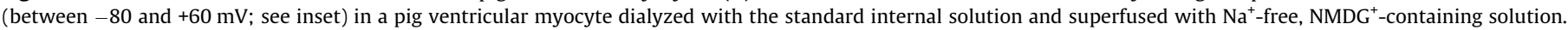

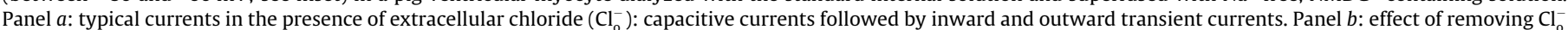

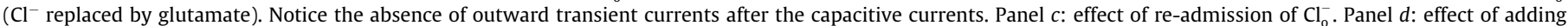

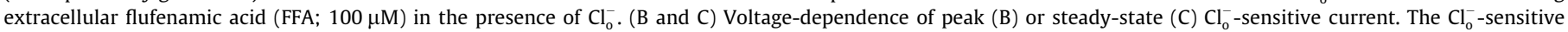
current was calculated as difference between the currents in the presence and after the removal of $\mathrm{Cl}_{0}^{-}$. The end-of-pulse current was taken as steady-state.

A untreated

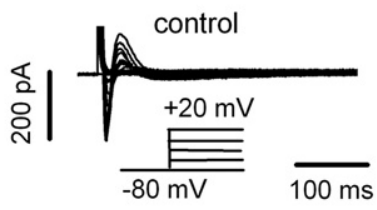

B ryanodine + BAPTA

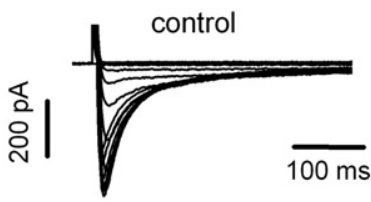

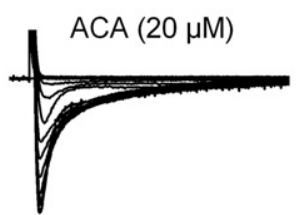

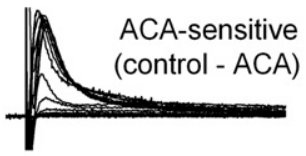

(control - ACA)
C

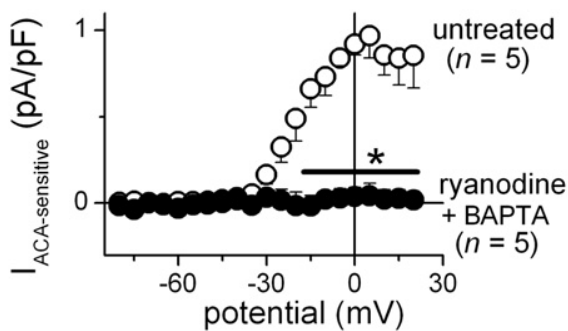

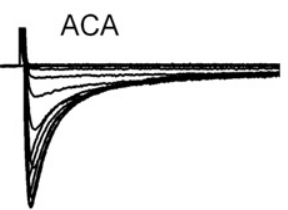
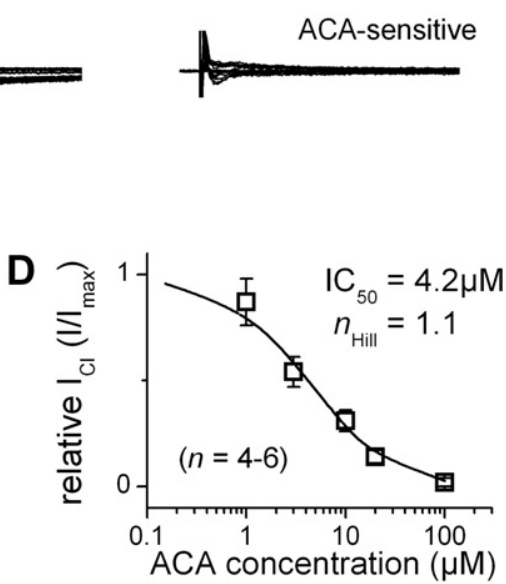

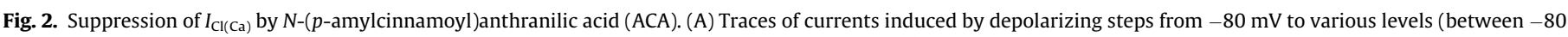

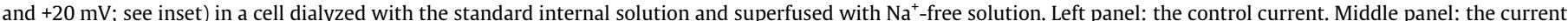

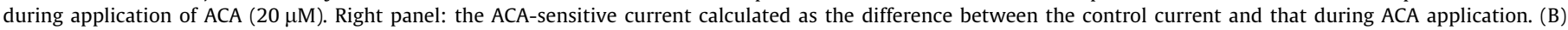

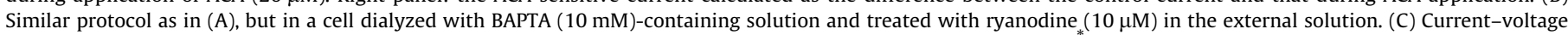

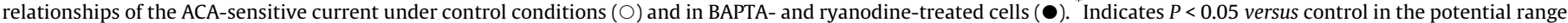

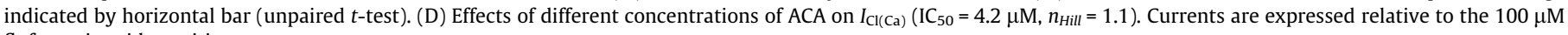
flufenamic acid-sensitive current.

symbols; at potentials $\geqslant-20 \mathrm{mV}, P<0.05$ versus untreated controls; unpaired $t$-test, $n=5$ ). These results indicate that the effect of ACA under standard conditions is due to a suppression of $I_{\mathrm{Cl}(\mathrm{Ca}) \text {, }}$ and that the drug has no effect on L-type $\mathrm{Ca}^{2+}$ channels. Similarly, 
A

ACA

anthranilic

flufenamic

acid

acid

diclofenac<smiles>CCCCCc1ccc(/C=C/C(=O)Nc2ccccc2C(=O)O)cc1</smiles><smiles>O=C(O)c1ccccc1Nc1cccc(OC(F)(F)F)c1</smiles><smiles>O=C(O)Cc1ccccc1Nc1c(Cl)cccc1Cl</smiles>

B
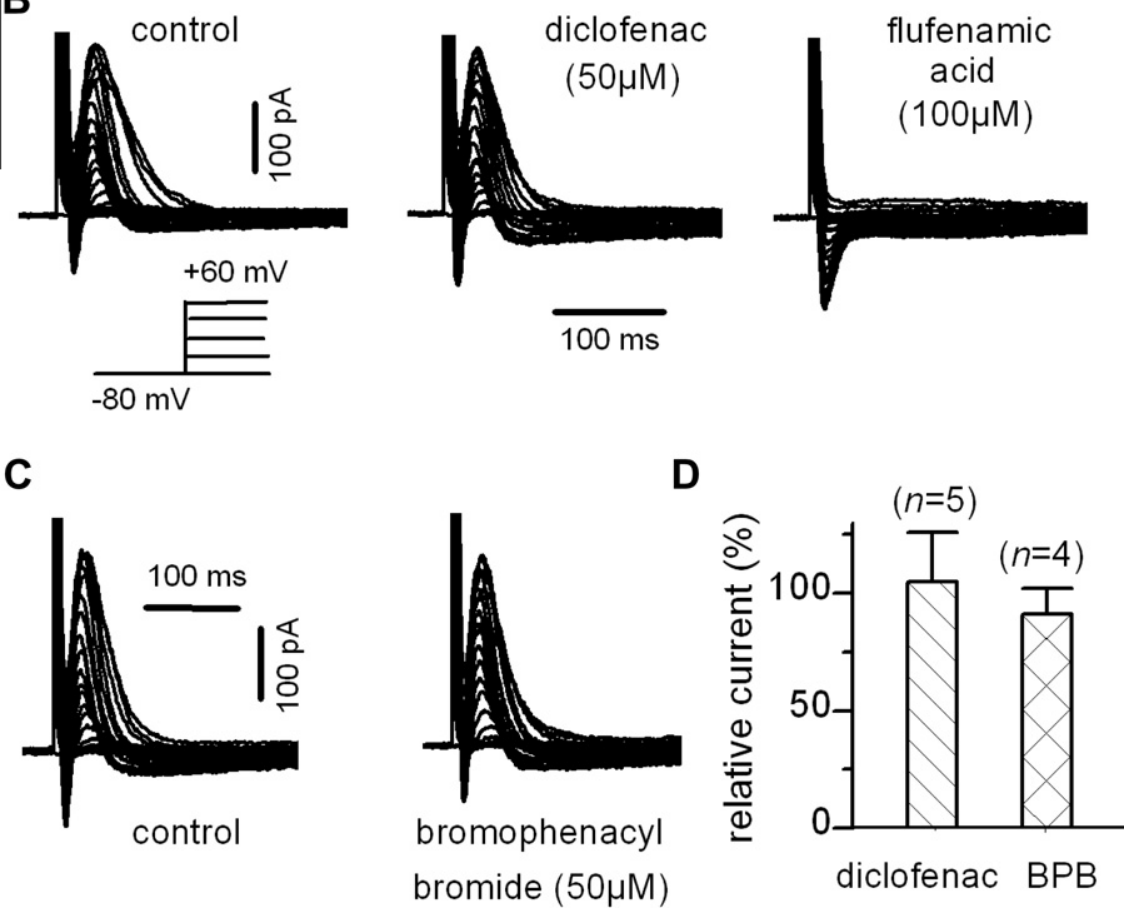

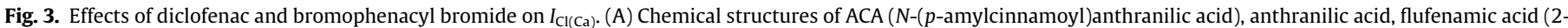

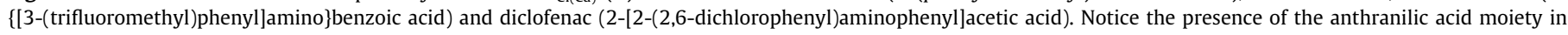

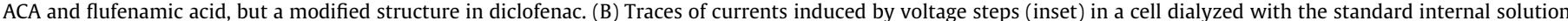

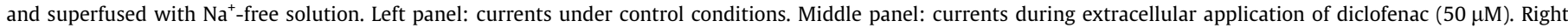

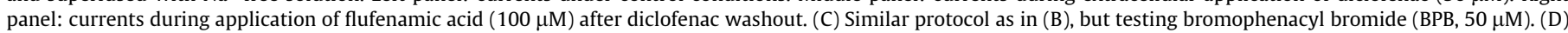
Summary data of drug effects on the transient outward currents. $P=0.502$ for diclofenac and $P=0.199$ for BPB, compared with control currents (paired $t$-test).

ACA had no effect on intracellular $\mathrm{Ca}^{2+}$ transients induced under voltage clamp (not illustrated).

The concentration-response curve of $I_{\mathrm{Cl}(\mathrm{Ca})}$ obtained when using different concentrations of ACA is illustrated in Fig. 2D. The effects of ACA can be described by a $50 \%$ inhibitory concentration $\left(\mathrm{IC}_{50}\right)$ of $4.2 \mu \mathrm{M}$ and a Hill coefficient $\left(n_{\text {Hill }}\right)$ of $1.1(n=4-6$ for each concentration).

\subsection{Effects of the NSAID diclofenac and the $P L A_{2}$ inhibitor bromophenacyl bromide}

Given that ACA and flufenamic acid are both fenamates and

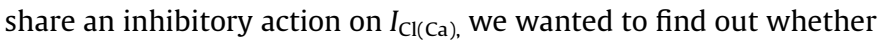
the fenamate-related drug, diclofenac, which is clinically used as a non-steroidal anti-inflammatory drug (NSAID), also inhibits $I_{\mathrm{Cl}(\mathrm{Ca}) \text {. }}$ Diclofenac $(50 \mu \mathrm{M})$ did not suppress the transient outward current (Fig. 3B; left versus middle panels), which at $+60 \mathrm{mV}$ was $105 \pm 21 \%$ of control (Fig. 3D; $P=0.502$ versus control; paired $t$-test, $n=5$ ), while in the same cells the current could be suppressed by flufenamic acid ( $100 \mu \mathrm{M}$; Fig. 3B, right panel). Similarly, $100 \mu \mathrm{M}$ diclofenac was ineffective in two other cells. In addition, because of the known phospholipase $A_{2}$ (PLA $)$ inhibitory effects of ACA [15], we also tested whether the enzyme could be involved in the action of ACA on $I_{\mathrm{Cl}(\mathrm{Ca})}$. The non-selective $\mathrm{PLA}_{2}$ inhibitor bromophenacyl bromide $(50 \mu \mathrm{M})$ failed to suppress the transient outward current, which was $91 \pm 11 \%$ of control (Fig. $3 C$ and $D ; P=0.199$ versus control; paired $t$-test, $n=4)$, suggesting that ACA effect on $I_{\mathrm{Cl}(\mathrm{Ca})}$ is $\mathrm{PLA}_{2}$-independent.

\subsection{Effects of ACA on the cAMP-activated $\mathrm{Cl}^{-}$current $\left(I_{\mathrm{Cl}(\mathrm{cAMP})}\right)$}

Having shown that ACA inhibits $I_{\mathrm{Cl}(\mathrm{Ca})}$, we wanted to compare its inhibitory effect on $I_{\mathrm{Cl}(\mathrm{Ca})}$ with its effect on another $\mathrm{Cl}^{-}$current, by testing its effect on the cAMP-activated current ( $I_{\mathrm{Cl} \text { (cAMP) }}$ ), also 
present in cardiac ventricular myocytes [20]. For this purpose, nifedipine $(100 \mu \mathrm{M})$ was included in external solutions to block $I_{\mathrm{Ca}, \mathrm{L}}, \mathrm{Na}^{+}$-containing, $\mathrm{Cs}^{+}$-based external solutions and the standard $\mathrm{Cs}^{+}$-containing pipette solutions were used, and the voltage clamp protocol consisted of ramps. The results are illustrated in Fig. 4. Forskolin, which is known to increase cAMP, induced an outward-rectifying current $(-1.4 \pm 0.10 \mathrm{pA} / \mathrm{pF}$ at $-120 \mathrm{mV}$ and $3.9 \pm 0.35 \mathrm{pA} / \mathrm{pF}$ at $+80 \mathrm{mV}$ ) with reversal potential of $-38.9 \pm 1.7 \mathrm{mV}(n=5)$, practically identical with the calculated equilibrium potential for $\mathrm{Cl}^{-}(-40.1 \mathrm{mV})$ under our experimental conditions. The outward component of the forskolin-activated current could be suppressed by decreasing $\mathrm{Cl}_{0}^{-}$, consistent with the view that the current is due to $\mathrm{Cl}^{-}$influx. ACA $(50 \mu \mathrm{M})$ decreased the forskolin-activated current to $55 \pm 3 \%$ at $-120 \mathrm{mV}$ and to $68 \pm 5 \%$ at $+80 \mathrm{mV}(P<0.05$ compared with the current in forskolin alone; paired $t$-test, $n=5)$. The reversal potential for the ACA-sensitive current was $-35.6 \pm 5.1 \mathrm{mV}(P=0.550$ compared with the reversal potential of the forskolin-induced current; paired $t$-test, $n=5$ ). Fig. 4B shows summary data of the above-mentioned effects and also illustrates the current-voltage relationships. Given that at $50 \mu \mathrm{M}$ ACA practically fully suppresses $I_{\mathrm{Cl}(\mathrm{Ca})}$ (see Fig. 2D), the drug is therefore a less effective inhibitor of $I_{\mathrm{Cl}(\mathrm{cAMP})}$ than it is of $I_{\mathrm{Cl}(\mathrm{Ca})}$.

\section{Discussion}

In the present study we show that a $\mathrm{Ca}^{2+}$-activated $\mathrm{Cl}^{-}$current $\left(I_{\mathrm{Cl}(\mathrm{Ca})}\right)$ is present in pig ventricular myocytes and that it is inhibited by $N$-( $p$-amylcinnamoyl)anthranilic acid (ACA). Our experimental conditions, using $\mathrm{Na}^{+}$-free external solutions and $\mathrm{K}^{+}$-free external and internal solutions, were designed to promote high intracellular $\left[\mathrm{Ca}^{2+}\right]$ levels $\left(\left[\mathrm{Ca}^{2+}\right]_{\mathrm{i}}\right)$ and to suppress any eventual $\mathrm{K}^{+}$-dependent transient outward current, respectively. We show that depolarizing voltage steps to potentials positive to $-40 \mathrm{mV}$ induce net inward currents that are short-lived and followed by transient outward currents. The latter currents were eliminated by omitting $\mathrm{Cl}_{\mathrm{o}}$, by externally applying known $\mathrm{Cl}^{-}$channel inhibitors such as flufenamic acid or DIDS, or by increasing the intracellular buffering of $\left[\mathrm{Ca}^{2+}\right]_{i}$ combined with an inhibition of $\mathrm{Ca}^{2+}$ release from the sarcoplasmic reticulum. Thus, our data are consistent with previous findings [19] showing the presence of $I_{\mathrm{Cl}(\mathrm{Ca})}$ in pig ventricular myocytes.

Transient outward currents $\left(I_{\mathrm{to}}\right)$ play an important role in the repolarization of the cardiac action potential. In most cases, $I_{\text {to }}$ is largely made of $\mathrm{K}^{+}$currents through $\mathrm{Kv} 4 . \mathrm{x} / \mathrm{Kv} 1.4$ channels. However, the expression of these channels differs among species. The currents are large in ventricular cells of rodents, but are absent or very small in ventricular myocytes of pig $[17,19]$ and guineapig [21]. There is still controversy concerning the mechanism underlying this lack of Kv4.x/Kv1.4-based currents in pig ventricular cells, with one study reporting lack of protein expression [19], whereas another showed their presence in non-conducting state [22]. Within the heart, the expression of $\mathrm{Kv} 4 . \mathrm{x} / \mathrm{Kv} 1.4$ channels is also region-dependent, being more prominent in subepicardial layers compared to mid-myocardial or subendocardial layers. The other type of $I_{\text {to }}$ found in cardiac cells is due to $I_{\mathrm{Cl}(\mathrm{Ca})}$, which we studied here. Because of its nature, $I_{\mathrm{Cl}(\mathrm{Ca})}$ is expected to be more prominent under conditions of intracellular $\mathrm{Ca}^{2+}$ overload. In a recent study, we showed that ACA depolarizes cardiac myocytes and also prolongs the action potential duration [23]. The latter effect of ACA may be related, at least in part, to the inhibition of $I_{\mathrm{Cl}(\mathrm{Ca})}$.

At present, with the molecular identity of $\mathrm{Ca}^{2+}$-activated $\mathrm{Cl}^{-}$ channels and their existence in the human heart still uncertain $[24,25]$, pharmacological agents continue to be a valuable tool in evaluating the contribution of the channels to net ion currents and to membrane potentials $[1,10]$. Our results show that ACA is

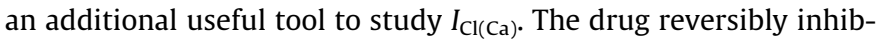
ited $I_{\mathrm{Cl}(\mathrm{Ca})}$ without affecting $I_{\mathrm{Ca}, \mathrm{L}}$. This inhibitory action occurred in a concentration range $\left(\mathrm{IC}_{50}=4.2 \mu \mathrm{M}\right)$ similar to the inhibition by flufenamic or niflumic acids ( $\mathrm{IC}_{50}$ range $2-108 \mu \mathrm{M}$; see [1]). Despite similar potencies, and despite the effect of ACA on other channels, ACA may be more advantageous than fenamates when studying $I_{\mathrm{Cl}(\mathrm{Ca})}$ because some of the latter drugs have been reported to affect $I_{\mathrm{Ca}, \mathrm{L}}$. The above-mentioned depolarization is due to the induction by ACA of a cation current [23], but this effect also occurs with less potency $\left(K_{0.5}=24 \mu \mathrm{M}\right)$ than the effect on $I_{\mathrm{Cl}(\mathrm{Ca})}$.

The mechanism underlying ACA effect on $I_{\mathrm{Cl}(\mathrm{Ca})}$ is unclear. ACA is a known $\mathrm{PLA}_{2}$ inhibitor [15], but its effects on $I_{\mathrm{Cl}(\mathrm{Ca})}$ are likely to be $\mathrm{PLA}_{2}$-independent because they could not be reproduced by the non-selective PLA $\mathrm{P}_{2}$ inhibitor bromophenacyl bromide. ACA has also been recently shown to inhibit some transient receptor potential (TRP) cation channels [26] in a PLA $_{2}$-independent manner. Flufenamic acid also inhibits several TRP channels (see [27]), implying a common underlying mechanism of action. Indirect mechanisms of inhibition of $I_{\mathrm{Cl}(\mathrm{Ca})}$ involving changes in $\mathrm{Ca}^{2+}$ are unlikely given the lack of ACA effect on $I_{\mathrm{Ca}, \mathrm{L}}$. Rather, because ACA also suppressed cAMP-activated $\mathrm{Cl}^{-}$currents, the drug could be acting as an anion channel inhibitor. Diclofenac, which is structurallyrelated to fenamates and to ACA, did not have similar effects on $I_{\mathrm{Cl}(\mathrm{Ca})}$, suggesting that structural differences between them may confer specific properties.

In conclusion, the present study shows that ACA suppresses cardiac $I_{\mathrm{Cl}(\mathrm{Ca})}$ in a concentration-dependent, but $\mathrm{PLA}_{2}$-independent
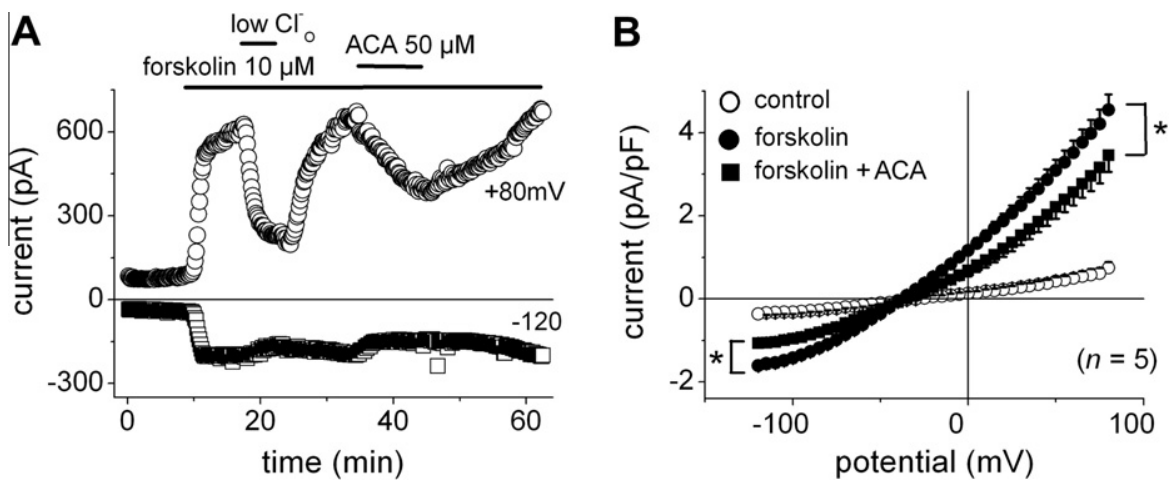

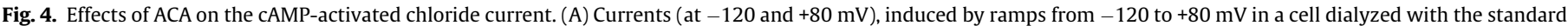

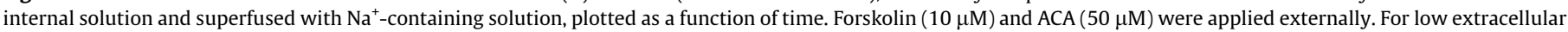

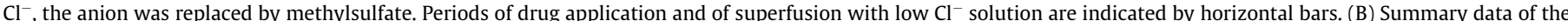

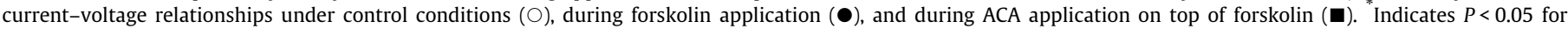
currents (at -120 and $+80 \mathrm{mV}$ ) in forskolin plus ACA versus forskolin alone (paired $t$-test) 
manner and without affecting $I_{\mathrm{Ca}, \mathrm{I}}$. The drug also suppresses cAMPactivated $\mathrm{Cl}^{-}$currents, but with a lower potency. ACA may, therefore, provide an additional experimental tool or serve as template for the design and development of new drugs useful in modulating anion channels.

\section{Acknowledgments}

This study was supported by Grant G.0634.07 from FWO, the Flemish Foundation for Science. R.M. was supported by grant SF/08/021 from the Research Council of the University of Leuven. A.G. was supported by the Belgian Technical Cooperation. We thank Elke DETRE and Christel HUYSMANS for help with cell dissociation.

\section{References}

[1] C. Hartzell, I. Putzier, J. Arreola, Calcium-activated chloride channels, Annu. Rev. Physiol. 67 (2005) 719-758.

[2] A.C. Zygmunt, W.R. Gibbons, Properties of the calcium-activated chloride current in heart, J. Gen. Physiol. 99 (1992) 391-414.

[3] M. Hiraoka, S. Kawano, Calcium-sensitive and insensitive transient outward current in rabbit ventricular myocytes, J. Physiol. 410 (1989) 187-212.

[4] G.N. Tseng, B.F. Hoffman, Two components of transient outward current in canine ventricular myocytes, Circ. Res. 64 (1989) 633-647.

[5] A.C. Zygmunt, W.R. Gibbons, Calcium-activated chloride current in rabbit ventricular myocytes, Circ. Res. 68 (1991) 424-437.

[6] K.R. Sipido, G. Callewaert, E. Carmeliet, $\left[\mathrm{Ca}^{2+}\right]_{i}$ transients and $\left[\mathrm{Ca}^{2+}\right]_{\mathrm{i}}$-dependent chloride current in single Purkinje cells from rabbit heart, J. Physiol. 468 (1993) 641-667.

[7] J.L. Kenyon, W.R. Gibbons, 4-Aminopyridine and the early outward current of sheep cardiac Purkinje fibers, J. Gen. Physiol. 73 (1979) 139-157.

[8] A.C. Zygmunt, R.J. Goodrow, C.M. Weigel, $I_{\mathrm{NaCa}}$ and $I_{\mathrm{Cl}(\mathrm{Ca})}$ contribute to isoproterenol-induced delayed after depolarizations in midmyocardial cells, Am. J. Physiol. 275 (1998) H1979-H1992.

[9] X. Han, G.R. Ferrier, Ionic mechanisms of transient inward current in the absence of $\mathrm{Na}^{+}-\mathrm{Ca}^{2+}$ exchange in rabbit cardiac Purkinje fibres, J. Physiol. 456 (1992) 19-38.

[10] J. Eggermont, Calcium-activated chloride channels: (un)known, (un)loved?, Proc Am. Thorac. Soc. 1 (2004) 22-27.

[11] J.M. Doughty, A.L. Miller, P.D. Langton, Non-specificity of chloride channel blockers in rat cerebral arteries: block of the L-type calcium channel, J. Physiol. 507 (Pt. 2) (1998) 433-439.
[12] A.S. Piper, I.A. Greenwood, W.A. Large, Dual effect of blocking agents on $\mathrm{Ca}^{2+}$ activated $\mathrm{Cl}^{-}$currents in rabbit pulmonary artery smooth muscle cells, J. Physiol. 539 (2002) 119-131.

[13] S.F. Cruickshank, L.M. Baxter, R.M. Drummond, The $\mathrm{Cl}^{-}$channel blocker niflumic acid releases $\mathrm{Ca}^{2+}$ from an intracellular store in rat pulmonary artery smooth muscle cells, Br. J. Pharmacol. 140 (2003) 1442-1450.

[14] A. Liantonio, V. Giannuzzi, A. Picollo, E. Babini, M. Pusch, D. Conte Camerino Niflumic acid inhibits chloride conductance of rat skeletal muscle by directly inhibiting the CLC-1 channel and by increasing intracellular calcium, Br. J. Pharmacol. 150 (2007) 235-247.

[15] R.J. Konrad, Y.C. Jolly, C. Major, B.A. Wolf, Inhibition of phospholipase $A_{2}$ and insulin secretion in pancreatic islets, Biochim. Biophys. Acta 1135 (1992) 215220.

[16] A. Gwanyanya, K.R. Sipido, J. Vereecke, K. Mubagwa, ATP and $\mathrm{PIP}_{2}$ dependence of the magnesium-inhibited, TRPM7-like cation channel in cardiac myocytes, Am. J. Physiol. Cell Physiol. 291 (2006) C627-C635.

[17] R. Macianskiene, F. Moccia, K.R. Sipido, W. Flameng, K. Mubagwa, Channels involved in transient currents unmasked by removal of extracellular calcium in cardiac cells, Am. J. Physiol. Heart Circ. Physiol. 282 (2002) H1879-H1888.

[18] A. Gwanyanya, B. Amuzescu, S.I. Zakharov, R. Macianskiene, K.R. Sipido, V.M. Bolotina, J. Vereecke, K. Mubagwa, Magnesium-inhibited, TRPM6/7-like channel in cardiac myocytes: permeation of divalent cations and $\mathrm{pH}-$ mediated regulation, J. Physiol. 559 (2004) 761-776.

[19] G.R. Li, X.L. Du, Y.L. Siow, K. O, H.F. Tse, C.P. Lau, Calcium-activated transient outward chloride current and phase 1 repolarization of swine ventricular action potential, Cardiovasc. Res. 58 (2003) 89-98.

[20] A. Bahinski, A.C. Nairn, P. Greengard, D.C. Gadsby, Chloride conductance regulated by cyclic AMP-dependent protein kinase in cardiac myocytes, Nature 340 (1989) 718-721.

[21] K.R. Sipido, G. Callewaert, F. Porciatti, J. Vereecke, E. Carmeliet, $\left[\mathrm{Ca}^{2+}\right]_{\mathrm{i}-}$ dependent membrane currents in guinea-pig ventricular cells in the absence of $\mathrm{Na} / \mathrm{Ca}$ exchange, Pflugers Arch. 430 (1995) 871-878.

[22] J.H. Schultz, T. Volk, P. Bassalay, J.C. Hennings, C.A. Hubner, H. Ehmke, Molecular and functional characterization of Kv4.2 and KChIP2 expressed in the porcine left ventricle, Pflugers Arch. 454 (2007) 195-207.

[23] R. Macianskiene, A. Gwanyanya, K.R. Sipido, J. Vereecke, K. Mubagwa, Induction of a novel cation current in cardiac ventricular myocytes by flufenamic acid and related drugs, Br. J. Pharmacol. 161 (2010) 416-429.

[24] A.O. Verkerk, M.W. Veldkamp, A. Baartscheer, C.A. Schumacher, C. Klopping, A.C. van Ginneken, J.H. Ravesloot, Ionic mechanism of delayed afterdepolarizations in ventricular cells isolated from human end-stage failing hearts, Circulation 104 (2001) 2728-2733.

[25] O.F. Koster, G.P. Szigeti, D.J. Beuckelmann, Characterization of a $\left[\mathrm{Ca}^{2+}\right]_{\mathrm{i}^{-}}$ dependent current in human atrial and ventricular cardiomyocytes in the absence of $\mathrm{Na}^{+}$and $\mathrm{K}^{+}$, Cardiovasc. Res. 41 (1999) 175-187.

[26] R. Kraft, C. Grimm, H. Frenzel, C. Harteneck, Inhibition of TRPM2 cation channels by $N$-( $p$-amylcinnamoyl)anthranilic acid, Br. J. Pharmacol. 148 (2006) 264-273.

[27] D.E. Clapham, Snapshot: mammalian TRP channels, Cell 129 (2007) 220. 